linear accelerator or the betatron for their nuclear work, which involves bombardment with $p, d, t$ and ${ }^{3} \mathrm{He}$ ions in the encrgy-range of up to $10-12 \mathrm{MeV}$. and direct measurement of nucloar life-times of $10^{-11}$ $10^{-14} \mathrm{sec}$.

There is an obvious need for accelerators going to even higher voltages, and Dr. P. Rose (High Voltage Engineering Co.) described plans for three-stage accelerators giving $15 \mathrm{MeV}$. He also foresaw accelerators furnishing $30-\mathrm{MeV}$. beams of 10 m.amp. within ten years. Other potential improvements in high-voltage accelerators includo millimicrosecond pulsing as compared with the $2-\mu$ sec. pulse at present available (R. Connor, High Voltage Engineering Co.) and more powerful genorators using the 'Amplitron' instead of the klystron or magnetron (J. C. Nygard, High-Voltage Engineering Co., and R. F. Post, California).

Ion sources of high efficiency, capable of separating $\mu \mathrm{gm}$. quantities of rare materials, were described by Prof. J. Kistemaker (Amsterdam), whilo Prof. R. Eleischmann (Erlangen) discussed polarized ion beams, and Dr. K. Beckurts (Karlsruhe) dealt with pulsed neutron sources and neutron life-time in moderators.

In radiation research, high-voltage beams are valuable in solid-state investigations, as outlined by Dr. P. Baruch (Paris) and have also been used in chemical analysis, either by gamma or neutron activation (J. W. Otvos, Emeryville). Radiation effects in biological systems, as presented by Dr. W. Huber (Stanford), particularly emphasized aspects of interest to radiation physicists and chemists dealing with radiation damage in much simpler systems.

The time-scale permitted adequate time for private discussions on many specific aspects which could not be raised at the formal sessions. Social activities included a banquet givon by the High Voltage Engineering Co., at which Prof. H. B. G. Casimir of the Philips Research Laboratories delivered a witty speech and a reception was held by the Mayor and Aldermen of Amsterdam. This included a Van Gogh exhibition which was very much appreciated. Scientific education is sometimes described as narrow and non-cultural. Perhaps we may hope that students of the humanities who hold this view also relax from their learned meetings by attending exhibitions of classical scientific experiments and reading or discussing recent developments in atomic structure, relativity and quantum theory, the basic concepts of which have an increasingly important influence on the outlook of the modern thinking man.

The full proceedings of the conference will be published at the end of the year in Nuclear Instruments and Methods.
A. Charlesby

\title{
FLOW MEASUREMENT IN CLOSED CONDUITS
}

$\mathrm{F}^{\mathrm{s}}$ LOW measurement is one of the less-spectacular aspects of fluid dynamics, and perhaps for this reason it has not received the attention it deserves. Nevertheless, flow-metering is as old as the engineering applications of fluid dynamics, since in almost every application it is desirable or important to know the volume or mass flow per unit time passing through the system. For example, the distribution of water in a water grid, the flow of air in an air-conditioning plant, the supply of steam to a turbine, the regulation of the flows in the continuous production of chemical engineering products. The fluids may be gases or liquids and the latter may be corrosive or contain solid suspensions as in sewage or wood pulp. The rate of flow may be small as in a blood vessel or great as in large hydraulie turbine installations and in gas turbines. The nature of the fluid, the size of installa. tion, the speed of flow and the accuracy required, all influence the choice of meter.

Of the more common types of flow-meter, the simplest and most accurate for measurements in liquids consists of a large vessel on a weighbridge into which a given mass of liquid is timed. The National Engineering Laboratory, East Kilbride, possesses a 30-ton weighing tank. Alternatively, a somewhat less accurate but more convenient method is that which uses a vessel designed on the pipette principle, into which a definite volume of liquid is timed. These two methods are generally used as standards against which more compact and convenient flowmeters may be calibrated. The pitot-static pressure head has been widely investigated, and used by aerodynamicists for measuring the velocity at a point in air flows, and is regarded by them as a fundamental instrument. By traversing the instrument across a duct the velocity distribution and hence the flux can be found. Small rotating vanes coupled to counting devices and known as current meters can also be uscd to find the velocity at a point after calibration, and hence the volume flow ean be found by integration. A great many meters in practical use utilize a pressure difference brought about by a change of cross-sectional area of the duct. In nozzles and venturi meters this change of area is smooth and gradual, and such meters introduce little loss into the duct system, but they are fairly sensitive to upstream disturbances. In the orifice-plate type of meter the change of section is sudden, and a largo resistance is offered to the flow, which gives rise to a large pressure difference. Another method, used in hydraulic power installations, involves the steady injection of a solution of salt at a known rate. Samples are then taken downstream where the mixing is complete, and from the dilution tho mass flow can be found. A variant of this makes use of radioactive isotopes. Some methods attempt to measure the mass or volume flow directly without introducing any obstruction into the duct. An interesting example is the magnetic flow-meter, in which a magnetic flux is set up at right angles to the flow of a conducting liquid, and a curront flows between two elcctrodes in the pipe wall which can be related to the volume rate-of-flow. The meter is of particular value in water-borne sludges. Another example of considerable practical importance is the Gibson method. In this the fairly rapid closure of a valve, or of the inlet guide vanes of a hydraulic turbine, causes a pressure variation with time bctween two stations in the pipe line. The integral of this over the time of closure is related closcly to the 
destruction of momentum and so to the mass-rate of flow.

During September 27-30 a symposium on "Flow Measurement in Closed Conduits" was held in the new James Watt building of the National Engineering Laboratory. It was the first of a series which are to be hold there, and so far as can be discovered, it was the first symposium devoted solely to flow measurement which has been held anywhere. Some 150 delegates were present; about 50 coming from countries of Western Europe, the United States and the Dominions and the remainder from British manufacturers, industrial users, official establishments and universities. The symposium occupied four days, and on the last evening the delegates attended a dinner at the Central Hotel, Glasgow, given by the director, Dr. D. G. Sopwith, to the authors of the papers. On the last afternoon, the delegates were invited to look around the various laboratories of the National Engineering Laboratory.

Dr. Sopwith was chairman at the opening session when the first item was the presentation of a film made by the National Engineering Laboratory at the Kinlochleven power-station, showing the comparative testing of a number of flow-meters. This was followed by the 'opening address' given by Vice-Admiral Sir Frank Mason, chairman of the Steering Committee of the National Engineering Laboratory. The remaining six sessions were devoted to the discussion of twenty-nine papers.

Session $A$ was concerned with surrent meters and pitot tubes, and included contributions from the United States (1), Italy (1), France (2), and the United Kingdom (2). Session $B$ discussed orifice plates, with papers from the United States (1), United Kingdom (2), France (1). Venturi-meters formed the subject of Session $C$, with papers from the United States (1), Belgium (2), and the United Kingdom (1). Session $D$ dealt with the various other pressure difference devices, with contributions from the United Kingdom (2), West Germany (1), Austria (1), and the United States (1). Session $E$ was devoted to salt dilution and salt velocity methods, with papers from the United States (1), France (1) and the United Kingdom (2). Session $F$ discussed the Gibson method, with papers from Norway (1), and the United Kingdom (1). Session $G$ was concerned with special methods, and papers were presented from the United Kingdom (3), West Germany and Holland (1). All papers were in English and the discussions were in English, and though translator services were available these were required but once. The papers and the discussions are to be published as a bound volume. The excellent organ. ization of the symposium by the deputy director, Dr. Hutton, and by Dr. Winternitz and his staff of the Fluid Mechanies Division of the National Engineering Laboratory, ensured that the maximum time was available for the discussion of the papers. The discussions were frank and helpful and were enlivened by certain overseas visitors with a nice sense of humour.

The theme of most of the papers and the discussions was the question of accuracy or constancy of the calibration coefficient. This is a very important feature of any flow-meter, and it was clear from the papers that considerable effort is being made to improve existing flow-meters in this respect. Presentday standards of accuracy for most flow-meters fall far short of those for physical measurements; for example, a reliable accuracy of 1 per cent must be regarded as rare. There are good reasons for this, since most flow-meters are affected by scale effects (Reynolds number), effects arising from upstream installations, such as bends and changes of section, turbulence and compressibility (in the case of gases), by erosion, corrosion and solid deposits which can cause deterioration with time. This question of accuracy is, in many cases, of great practical importance. In chemical engineering, accurate metering and regulation of the flow of the various products in continuous-flow processes is desirable on both technical and economic grounds. The manufacturers of pumps and turbines are frequently called on (in the case of large units) to meet very stringent performance specifications, which involve quantity flow, and it is essential that the manufacturer and the user should agree on the flow-metering accuracy. Since many countries export turbo-machinery, flow-metering has an international importance. One of the important results achieved by the symposium was not only the bringing together of the manufacturers, users and research workers, but also the achieving of this on an international level, so that a wide variety of experience was pooled and important personal contacts were made.

In conclusion, therefore, it can be stated that the symposium was timely and a great success, due mainly to the excellent arrangements made by the Fluid Mechanics Division of the National Engineering Laboratory.
J. H. Preston

\section{PROGRESS IN CALORIMETRY}

\begin{abstract}
T HE fifteenth annual Calorimetry Conference was held at Gatlinburg, Tennessee, during September 7-10, with Oak Ridge National Laboratory acting as host and Dr. J. P. MeCullough (Petroleum Thermodynamics Laboratory, Bureau of Mines) serving as chairman. In the pleasant surroundings of the Great Smoky Mountains, 106 calorimetrists from the United States, Canada and Europe heard and discussed thirty-one technical papers on recent work on many phases of calorimetry and engaged in informal discussions of calorimetric problems. Among the topics discussed were calorimetry at temperatures
\end{abstract}

as low as $0 \cdot 1^{\circ} \mathrm{K}$. and as high as $2,800^{\circ} \mathrm{K}$, precision reaction and bomb calorimetry, solution calorimetry, applications of calorimetry to solid-state problems, application of calorimetry to radiation dosimetry, improvements in temperature measuring devices, and data processing by digital computers. At the Conference banquet, Dr. A. M. Weinberg, director of Oak Ridge National Laboratory, shared his experiences and observations on a recent trip to the U.S.S.R. with the chairman of the U.S. Atomic Energy Commission, illustrating his talk with a number of interesting slides. Dr. D. W. Osborne 